\title{
DILEMA NA SUSTENTABILIDADE URBANA: A DISPOSIÇÃO DA POPULAÇÃO EM MIGRAR DO TRANSPORTE INDIVIDUAL PARA O COLETIVO
}

\author{
Archimedes Azevedo Raia Junior ${ }^{1}$ \\ Patrícia Baldini Medeiros ${ }^{2}$ \\ Flávio Toshiki Imae Nishimori ${ }^{3}$ \\ Guilherme Burgo Raia ${ }^{4}$
}

\section{RESUMO}

Nas últimas décadas, os problemas ambientais urbanos se tornaram um dilema e têm se intensificado indicando que ações sejam implantadas para a sua mitigação. O cidadão, neste cenário, é um ator importante para a transformação da sociedade, visando melhor qualidade de vida. Ouvi-lo pode dar indícios ao gestor público de como agir no desenvolvimento de políticas públicas voltadas à sustentabilidade urbana. Uma pesquisa foi feita, via internet, onde se lançou a questão: você trocaria seu carro por um transporte público ou alternativo? Por quê? As manifestações foram apresentadas espontaneamente. As respostas passaram por processos de leitura, filtragem, tratamento e sistematização; posteriormente, foram associadas a variáveis. A análise dos dados apontou, como resultados mais importantes, que $21 \%$ foram favoráveis à troca e $30 \%$ não; 42\% concordariam em substituir o transporte individual desde que o coletivo melhorasse. Os poderes executivo, legislativo e "econômico" foram apontados, respectivamente, por $27 \%, 15 \%$ e $6 \%$, como responsáveis pelo caos no transporte.

\footnotetext{
${ }^{1}$ Doutor Eng., Programa de Pós-Graduação em Engenharia Urbana da UFSCar, Professor Associado raiaj@@ufscar.br

${ }^{2}$ Eng. Civil, Programa de Pós-Graduação em Engenharia Urbana da UFSCar, Mestranda patriciabmedeiros@hotmail.com

${ }^{3}$ Geógrafo, Programa de Pós-Graduação em Engenharia Urbana da UFSCar, Mestrando flaviotoshiki@yahoo.com.br

${ }^{4}$ Biólogo, Universidade do Sagrado Coração-SENAC-Bauru - guilhermebg.raia@gmail.com
} 
Palavras-chave: Impactos ambientais. Transporte urbano. Ambiente urbano.

\section{INTRODUÇÃO}

O panorama da circulação, principalmente nas grandes cidades, aponta para: trânsito caótico; muitas horas perdidas em congestionamentos, inúmero acidentes envolvendo motos, automóveis, caminhões, ônibus e os pedestres; poluição sonora das buzinas e dos roncos dos veículos; poluição do ar gerada pelos veículos, lançando enormes quantidades de gases tóxicos, responsáveis pelo aceleramento do processo de aquecimento global, etc. No mundo todo, morrem cerca de 800 mil pessoas por ano, devido às doenças causadas por essa poluição (WHO, 2002). Uma das consequências é que as cidades vêm sofrendo um processo progressivo de degradação que, neste caso, compromete a qualidade de vida da população e o meio ambiente. É necessária uma nova alternativa que produza o desenvolvimento urbano com o enfoque sustentável, privilegiando transportes mais eficientes do ponto de vista energético e ambiental. Uma opção mais viável para esse procedimento aponta para o transporte coletivo, que tem por principal objetivo deslocar seus usuários, no espaço urbano, para a realização de suas necessidades diárias. Ele deve contribuir para a melhoria da qualidade de vida da população sem, contudo, torná-la conflituosa.

Todavia, o transporte urbano, hoje, no Brasil, tem no modo individual motorizado (automóveis e motos) um dos principais meios de transportes, e é um dos mais diretamente responsáveis pelos problemas urbanos. Com isso, pode-se constatar que medidas que viabilizem um sistema de transporte sustentável poderão contribuir de modo significativo para a melhoria na qualidade de vida das cidades. Em vista disso, é preciso que se promova a troca do modo individual motorizado por modos coletivos alternativos, 
com o intuito de se contornar a severa situação criada sobre o ambiente urbano. Contudo, por estar arraigado no cerne do pensamento da população brasileira, o automóvel e a moto passaram a ser considerados, além de um símbolo de status social, um mal necessário para atender os seus objetivos individuais.

Observa-se que a transição para um modo mais sustentável, encontra diversas barreiras que se inicia a partir do forte lobby das indústrias automobilísticas, que defendem de maneira feroz o marketing sobre o uso dos automóveis e motos (publicidade pró-carro e moto). Aliado a esta situação, o Governo provê incentivos fiscais como a diminuição do Imposto sobre Produtos Industrializados (IPI) sobre os automóveis, reduzindo, assim, os seus preços. Além disso, é promovida a facilidade no acesso ao crédito que possibilita o financiamento de longo prazo, com baixas taxas de juros, para a aquisição de automóveis e motos. Adicionalmente, o desenvolvimento da tecnologia que possibilita a utilização de dois combustíveis no mesmo veículo, o chamado total flex, que já está disponível também para motos, permite ao usuário do modo motorizado individual a escolha do combustível (gasolina ou álcool) com o preço que melhor satisfaz o orçamento. A decorrência é um maior uso dos veículos, com preços menores de combustíveis.

Um dos pontos que se pode destacar, é que o veículo individual passa uma sensação de liberdade ao seu usuário, já que apresenta as vantagens de liberdade horária (podendo sair de seu local de origem para o seu local de destino sem horário prédefinido); na liberdade de escolha do trajeto a ser seguido (com múltiplos destinos seguidos em uma mesma viagem), atendimento porta a porta (sem deslocamento intermediário entre a origem ou destino); a individualidade e o conforto, já que pode ter a opção de não ter companhias na viagem, como ocorre nos transportes coletivos, como também poderá viajar sentado, aproveitado as comodidades que 0 automóvel proporciona, como ar-condicionado, aparelho de som, etc. (Frederico et al., 1997). 
As pessoas que utilizam seus veículos particulares se adaptam à situação caótica criada pelo trânsito e, em alguns momentos, utilizam estratégias para poder burla-lo. Neste caso, as pessoas tendem a sair mais cedo de suas casas com o objetivo de chegar a tempo em seu local de trabalho evitando, assim, o horário de rush, característico das grandes cidades. Quando o motorista encontra o trânsito lento, ele pode utilizar rotas alternativas para não enfrentar o congestionamento; quando a situação é inevitável, ele utiliza o ar-condicionado do automóvel, ouve musicas, dentre outros artifícios para manter o seu conforto. O condutor da moto, por sua vez, não dispensa a possibilidade da extrema agilidade deste veículo para circular por entre as filas de automóveis. Diferentemente das pessoas que não possuem automóveis ou motocicletas, tantas outras necessariamente utilizam o sistema coletivo, geralmente de baixa qualidade, e convivem com a falta de conforto causada pela superlotação.

Em função deste panorama de comportamento da população, voltado para o uso de modos motorizados individuais, o objetivo deste trabalho é apresentar os resultados de uma pesquisa exploratória, com o intuito de conhecer a predisposição que a população tem em substituir meios motorizados individuais pelo coletivo, como alternativa à melhoraria de congestionamentos, barulho, poluição do ar, acidentes em cidades brasileiras, e sua preocupação com o meio ambiente.

\section{MOBILIDADE URBANA SUSTENTÁVEL}

A discussão em questão remete à diminuição dos impactos causados pela ação antrópica sobre o meio ambiente. O relatório Mobilidade 2030, elaborado por World Business Council for Sustainable Development (WBCSD/CEBDS, 2004), preve algumas medidas para tornar a mobilidade mais sustentável, que permita melhor desenvolvimento urbano e um aumento considerável da qualidade de vida da população. Este estudo 
procura refletir o fato de que o aumento no uso irrestrito dos veículos individuais provoca aumento na poluição, tanto do ar como sonora e do solo. O relatório também aponta para a gravidade no aumento do número de acidentes causados por automóveis e motocicletas. Segundo Boarnet e Crane (2001) citados por WBCSD/CEBDS (2004), o problema reside no fato de que os automóveis não têm projetos de remediação aos efeitos colaterais (externalidades) por eles causados: congestionamentos, poluição do ar, impactos causados na qualidade de vida das comunidades, etc. Outra questão importante é a econômica. Fruto do aumento do "preço" dos deslocamentos causados pelas consequências das externalidades, este aspecto é retratado como custos externos. Ao motorista se apresenta a opção em escolher entre duas opções: a primeira é sair mais cedo de sua residência evitando o tráfego intenso e não pagando pelos custos externos; a outra, é que ele arcará com os custos externos de sua decisão.

Mas, a grande questão que se apresenta é que a solução para esta situação de congestionamento, que afeta tanto o usuário do transporte coletivo como o próprio usuário do transporte motorizado individual, não remete apenas à taxação daqueles que utilizam o veículo individual, mesmo que a arrecadação resultante seja usada para minimizar os problemas gerados pelo segundo grupo de indivíduos. O correto seria o gerenciamento da demanda, ou seja, reduzir a necessidade de se deslocar (WBCSD/CEBDS, 2004).

Outro trabalho, também realizado a partir de análises sobre as respostas de uma enquete pela internet, apontava preocupação com a percepção e sensibilização da população de São Paulo com os impactos ambientais e de sustentabilidade causados pelo trânsito caótico e os problemas usos do automóvel. Raia Jr. et al (2008) concluíram que, dentre as 86 pessoas que responderam a pesquisa, $26 \%$ sugeriram investimento no transporte coletivo, 9,8\% disseram que a restrição ao uso dos veículos motorizados seria uma solução; $8,1 \%$ destacaram o investimento em veículos não motorizados e 5,7\% entendiam que a diminuição do trânsito estaria ligada ao investimento em infraestrutura viária. O restante $(25,2 \%)$ dos respondentes não apresentou nenhuma proposta. 
Quando questionados sobre quem teria culpa pela situação caótica do trânsito, $37,2 \%$ apontaram os governantes e o poder público como os responsáveis; $16,3 \%$ passaram a responsabilidade dos problemas para a população. Contudo, o que mais chamou a atenção na análise apresentada por Raia Jr. et al. (2008), foi a pequena porcentagem de pessoas $(10,5 \%)$ que se preocuparam com a questão ambiental.

Ao destacar este quadro de insustentabilidade apresentado até aqui, observa-se a necessidade de se investir em mobilidade sustentável, através da diminuição do número de veículos individuais e a transferência destes usuários para os meios coletivos. Além disso, utilizar novas fontes renováveis de energia, com o intuito de diminuir a poluição do ar. Também é necessário maior investimento sobre os transportes coletivos, para que ocorra maior oferta com melhor qualidade dos serviços prestados.

É importante salientar que o modo básico de transporte utilizado pela população é o modo a pé, ou seja, o ato de exercer a caminhabilidade é o primeiro passo para melhar da qualidade da mobilidade. Este nível atinge a todos, até aqueles que utilizam o veículo particular, pois, para acessar e depois deixar o veiculo, as pessoas necessitam deslocarse caminhando. Investimentos em acessibilidade são essenciais para que todas as pessoas possam se deslocar de modo seguro e com autonomia até o transporte coletivo.

Investimento em modos não motorizados, como o do modo cicloviário, é essencial, já que este tipo de transporte não gera poluição como os veículos motorizados. Neste caso destaca-se apenas a poluição gerada desde a fabricação da bicicleta até sua utilização, incluindo o ato de manutenção. Na verdade, este fato ocorre também com a fabricação de outros modos (automóvel, trem, metrô, etc.). Os investimentos em faixas exclusivas para ciclistas, bicicletários nas imediações de terminais de transporte, são importantes para a migração do transporte individual motorizado para o cicloviário. 
Os investimentos nos transportes coletivos, como é o caso do transporte rápido por ônibus (BRT), metrôs, veículos leves sobre trilhos (VLT), são necessários para o atendimento das necessidades diárias de deslocamentos da massa de usuários. Contudo, a opção para utilizar os transportes de massa depende muito do nível de serviço por eles oferecidos. O tempo gasto em deslocamentos é um dos fatores determinantes para a escolha do usuário em relação ao transporte a ser utilizado. No entanto, os usuários só percebem os tempos com os veículos em deslocamento. Entretanto, verifica-se que os tempos totais de deslocamento são muito diferentes dessa percepção ilusória. A Tabela 1 traz dados sobre as distâncias e os tempos de deslocamentos nas varias etapas de uma viagem por transporte coletivo de massa. Os dados da Tabela mostram que o BRT é aquele que apresenta o menor tempo total de viagem (26 minutos), considerando um percurso de 10 km, seguido por metrô (29), VLT (34) e, o mais demorado é o ônibus (38).

Tabela 1: Tempo gasto em deslocamentos por modos coletivos

\begin{tabular}{|c|c|c|c|c|c|}
\hline DESLOCAMENTOS & & METRÔ & BRT & VLT & ÔNIBUS \\
\hline \multirow{2}{*}{ Acesso à estação } & Distância & $500 \mathrm{~m}$ & $250 \mathrm{~m}$ & $250 \mathrm{~m}$ & $200 \mathrm{~m}$ \\
\hline & Tempo & 7,5 & 3,9 & 3,9 & 3,0 \\
\hline \multirow[t]{3}{*}{ Acesso à plataforma } & Distância & $200 \mathrm{~m}$ & - & - & - \\
\hline & Tempo & 3,0 & - & - & - \\
\hline & Pagamento & 0,1 & 0,1 & 0,1 & 0,1 \\
\hline \multirow[t]{2}{*}{ Viagem $(10 \mathrm{~km})$} & Velocidade & $40 \mathrm{~km} / \mathrm{h}$ & $27,5 \mathrm{~km} / \mathrm{h}$ & $20 \mathrm{~km} / \mathrm{h}$ & $17 \mathrm{~km} / \mathrm{h}$ \\
\hline & Tempo & 15,0 & 22,0 & 30,0 & 35,3 \\
\hline \multirow[t]{2}{*}{ Acesso à rua } & Distância & $200 \mathrm{~m}$ & - & - & - \\
\hline & Tempo & 3,0 & - & - & - \\
\hline TEMPO TOTAL & & 28,6 & 26,0 & 34,0 & 38,4 \\
\hline
\end{tabular}

Fonte: JLAA (2009)

A diferença básica entre os modos de transporte de massa consiste no custo, tempo de implantação e sua capacidade. O BRT, apesar de transportar menos passageiros que o metrô, consegue ser implantado em menos tempo e assim consegue acompanhar a expansão da cidade, levando o transporte público para as áreas de expansão. Mas, para áreas de grande demanda de passageiros (acima de 30.000 passageiros por hora), ele pode se tornar insuficiente. Por isso, a comparação entre custo 
e benefício deve ser avaliada para cada tipo de cidade e suas necessidades. A Figura 1 ilustra uma comparação entre as capacidades médias e os custos de investimentos para o BRT, VLT, metrô e trem metropolitano.

Outro fator que pesa na escolha do modo de transporte pelo usuário é o conforto que cada tipo oferece. Segundo JLAA (2009), o nível de conforto para o passageiro é determinado por um conjunto de fatores independentes, dentre eles o contato e a convivência com a paisagem do percurso e sua relação com a cidade: i) a qualidade do veículo, em termos de aceleração e frenagem, ruídos internos e externos, acessibilidade (ausência de escadas ou longas rampas) e temperatura ambiental (ar condicionamento); ii) a qualidade das estações, também em termos de ruídos internos e externos, acessibilidade e temperatura ambiental; iii) a qualidade do acesso às estações, em termos de segurança, ausência de escadas, faixas seguras para a travessia de vias, calçadas e paisagismo decentes, e proteção (onde possível) de sol e chuva; e iv) a qualidade operacional, ou seja, o número de passageiros por metro quadrado.

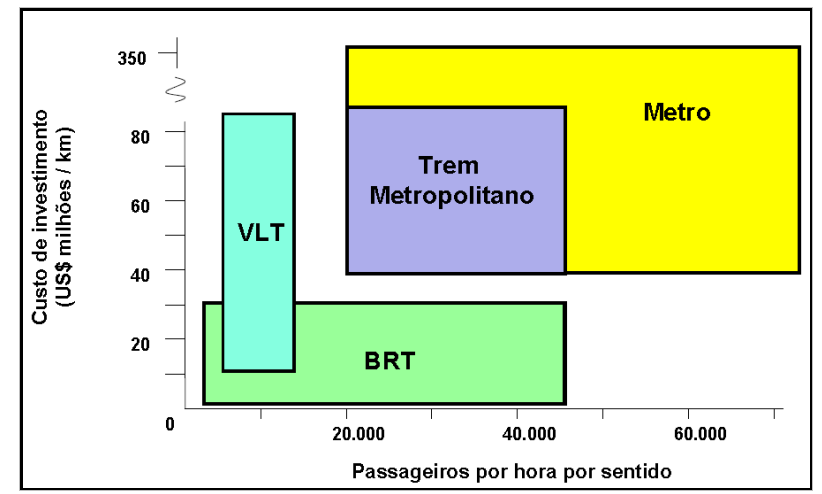

Figura 1 Relação entre custos e capacidades de tipos de transporte de massa

Fonte: Hagen (2010)

Assim, a qualidade do veículo do metrô tende a ser superior à do veículo do BRT; os outros dependem inteiramente de projetos complementares. Se na região onde o usuário do transporte coletivo reside ou trabalha não há estações próximas ou elas 
inexistem, a escolha pelo modo individual poderá ser uma constante, se for levado em conta esta questão do conforto.

\section{METODOLOGIA}

O objetivo deste trabalho é apresentar uma análise dos dados colhidos em uma pesquisa exploratória destinada a conhecer a opinião dos leitores a respeito da predisposição do usuário na troca do transporte individual por um transporte alternativo ou público. A questão foi apresentada no âmbito de uma matéria do site UOL Notícias, que mostrava o aumento do número de veículos adquiridos na cidade de São Paulo, no período de um ano. Adicionalmente, uma breve explanação sobre os problemas de congestionamento e trânsito na cidade foi apresentada por um jornalista (Balza, 2009):

A frota de veículos no Estado de São Paulo recebeu, entre junho de 2008 e junho de 2009, o aporte de 1,2 milhão de unidades e atingiu a marca de 19,5 milhões, segundo dados do Detran (Departamento Estadual de Trânsito de São Paulo). A cidade de São Paulo ainda concentra maior quantidade de veículos por habitante, mas o maior aumento da frota, em números relativos e absolutos, ocorreu fora da capital (interior, litoral e municípios da Região Metropolitana).

Só na cidade de São Paulo já são 6,55 milhões de veículos, entre carros, motos, vans, utilitários, caminhões, ônibus, entre outros. Se todos os veículos fossem colocados na rua ao mesmo tempo, seriam necessárias duas capitais e meia, levando em conta que a cidade possui $16 \mathrm{mil} \mathrm{km}$ de vias e considerando que o tamanho médio de um veículo é de aproximadamente 6 metros. Enfileirados, os veículos dariam uma volta completa no planeta Terra, que possui cerca de 40 mil km de circunferência.

A proporção na capital - que, segundo estimativa do IBGE (Instituto Brasileiro de Geografia e Estatística), possui atualmente 11 milhões de habitantes - é de um veículo para 1,68 morador. No Estado (com 41,4 milhões de habitantes), a proporção é de um veículo para 2,12 moradores. Já se a cidade de São Paulo for excluída do cálculo, a proporção é de um veículo para 2,34 habitantes.

Nos últimos dez anos, a frota de veículos no Estado recebeu 7 milhões de novas unidades, saltando de 11,9 milhões em janeiro de 1999 para 18,9 milhões no mesmo mês deste ano. Considerando o crescimento médio da frota nos últimos 17 anos - em torno de 110 mil unidades - a estimativa é que o Estado tenha atualmente 19,7 milhões de veículos e ultrapasse a marca de 20 milhões em dezembro. 
Junto à matéria havia uma questão dirigida ao leitor Você trocaria seu carro por um transporte público ou alternativo?, como mostra a Figura 2.

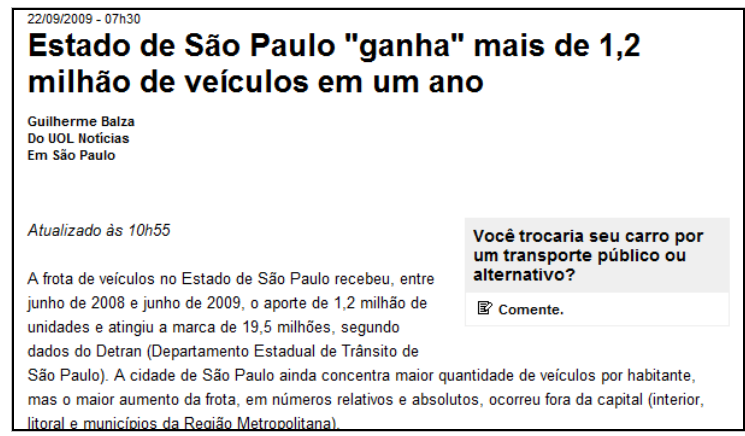

Figura 2 Detalhe do site da pesquisa

Fonte: Balza (2009)

Os procedimentos metodológicos para o desenvolvimento deste trabalho pode ser resumidos nas seguintes etapas: i) aquisição dos comentários junto ao site da pesquisa; ii) desenvolvimento de uma planilha eletrônica para inserção dos dados da pesquisa (ID, nome, sexo, cidade/estado de origem, dia e hora do comentário, comentário, tipo de transporte alternativo, se trocaria o carro pelo transporte público ou alternativo, responsáveis pelo problema, etc.); iii) processo de "leitura" dos comentários apresentados na reportagem e sua interpretação, procurando extrair informações importantes para análise; iv) a partir da leitura do item anterior, procurou-se extrair os modos de transporte que as pessoas "trocariam", além de atribuições aos possíveis responsáveis pela situação de calamidade do trânsito em São Paulo, ou seja, críticas aos gestores/governantes, à população. Por último, verificar se diante do quadro apresentado o participante da pesquisa manifestava alguma preocupação com o meio ambiente; v) filtragem dos comentários para verificação de pertinência de dados; vi) inserção dos dados na planilha eletrônica; vii) tratamento e sistematização os dados; e viii) análise e conclusões.

\section{APLICAÇÃO, RESULTADOS E ANÁLISE}


No período de 21.09.09 a 07.10.09, 66 leitores participaram da pesquisa exploratória através de seus comentários, que foram identificados pelo seu primeiro nome. Os dados relativos a cada comentário foram introduzidos em planilha eletrônica, organizando-se os dados segundo os campos previstos (ID, nome, sexo, estado de origem, dia e hora do comentário, comentário, tipo de transporte alternativo que utilizaria e possíveis responsáveis pelo problema), como mostra a Figura 3.

\begin{tabular}{|c|c|c|c|c|c|c|c|c|c|c|c|c|c|c|c|c|c|}
\hline A & 8 & \multirow{2}{*}{\multicolumn{3}{|c|}{$\begin{array}{c}D \\
\text { ORIGEM }\end{array}$}} & \multirow{2}{*}{\multicolumn{2}{|c|}{ SEXO }} & \multirow{2}{*}{\multicolumn{2}{|c|}{$\begin{array}{l}\text { H T } \\
\text { DATA }\end{array}$}} & \multirow{2}{*}{\multicolumn{2}{|c|}{ bCA COND ATU }} & \multirow{2}{*}{\multicolumn{3}{|c|}{$\begin{array}{lll}\text { M } & \text { N } \\
\text { OOCA MELL COM OUTRO }\end{array}$}} & \multirow{3}{*}{\begin{tabular}{|c|} 
W \\
PREOC \\
SUSTENT
\end{tabular}} & \multirow{2}{*}{\multicolumn{3}{|c|}{$\begin{array}{ccc}X & Y & ? \\
\text { CULPA PELO QUADRO }\end{array}$}} \\
\hline & & & & & & & & & & & & & & & & & \\
\hline Ord & NOME & INTER & CAPITAL & Estado & MASC & FEM & DIA & HORA & SIM & NÃO & SIM & MÃO & MODO? & & EXECUT & LEGISL & PODECON \\
\hline 41 & Alexandre & & 1 & sp & 1 & & $22 /$ set & $12: 26$ & & 1 & & & & & & & \\
\hline 42 & Cristina & & 1 & sp & & 1 & $22 /$ set & $12: 20$ & & & 1 & & pé/bus & & & & \\
\hline 43 & FranciscoSaes & & 1 & sp & 1 & & $22 /$ set & $12: 19$ & & & 1 & & & 1 & 1 & 1 & \\
\hline 44 & Cristina & & 1 & sp & & 1 & $22 /$ set & $12: 18$ & & & 1 & & pé/bus & & & & \\
\hline
\end{tabular}

Figura 3 Detalhe da planilha eletrônica para inserção e tratamento dos dados

Para exemplificar, a seguir, são apresentados 3 comentários, mantidos em sua forma original, sem nenhum tipo de correção do texto:

Eu acredito que se eu tivesse alternativa de transporte coletivo decente, pelo menos, $45 \%$ das minhas necessidades eu utilizaria essa opção. Considerando a total falta de segurança e o mínimo de conforto, enquanto eu tiver condições, eu não largo o meu carro mesmo que eu tenha que ficar horas no trânsito. Os governantes e legisladores pouco fazem para melhorar essa situação... Suas formulas são sempre a de punir o cidadão pelo que ele não tem a responsabilidade direta. Ando de ônibus quando os governantes e legisladores andarem, coloco meus filhos na Escola Pública quando os mesmos colocarem e uso Hospital Público, quando eles usarem também, nas mesmas condições que qualquer cidadão 'comum' usa” (Fúlvio).

Sim, trocaria. Mas acho que a solução pra o caos no transito de SP é o metro, este deve chegar cada vez mais aos pontos mais importantes de cidade, tais como aeroportos, etc, e ir mais longe, ou seja, avançar nas cidades periféricas, tais como, Embu, $A B C D$, sem contar com trens eficientes, que cheguem a Campinas, Sorocaba e quem sabe um dia litoral (Ricardo).

Trocaria tranquilamente, desde que houvesse transporte público neste país... Infelizmente as ruas ficam cada vez mais superlotadas de carros, nas cidades grandes e de médio porte. O governo federal alimenta o consumismo do brasileiro e a poluição do ar, incentivando a compra de carros. Ninguém se preocupa em melhorar o transporte público, com a construção de metrôs, vias férreas e 


\section{Periódica Eletrânica

melhoria dos ônibus e seus corredores. Francamente, tenho muita pena das pessoas que dependem de transporte coletivo neste país (Marília).

Um aspecto interessante a se conhecer é a origem dos participantes da pesquisa. Como se pode verificar na Figura 4, a maior participação foi de pessoas residentes em São Paulo - capital e interior - com 73\%, mas com expressiva participação de pessoas da capital, onde a gravidade dos problemas do trânsito tem dimensões maiores que nas cidades do interior (Figura 5).

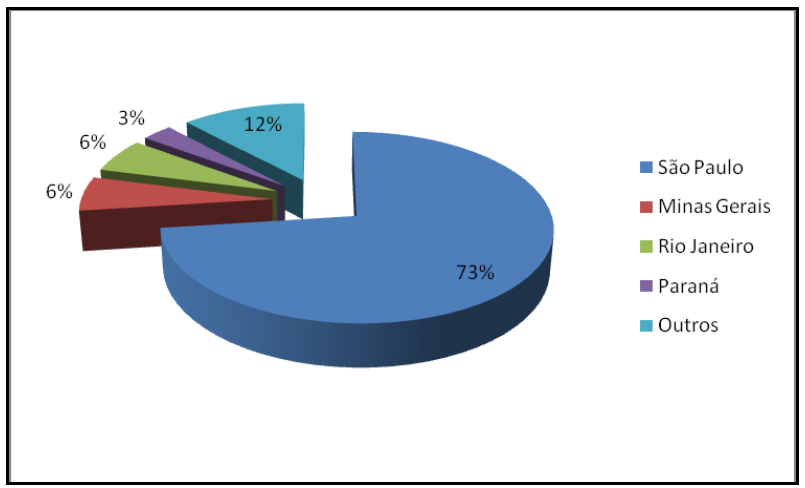

Figura 4 Participação de pessoas, segundo o estado de origem (\%)

A maior participação de paulistas na pesquisa provavelmente se deve ao fato da matéria do site se referir aos dados da capital São Paulo, embora a realidade seja também crítica em muitas outras capitais brasileiras e cidades do interior, demonstrado pela também participação de representantes dessas cidades.

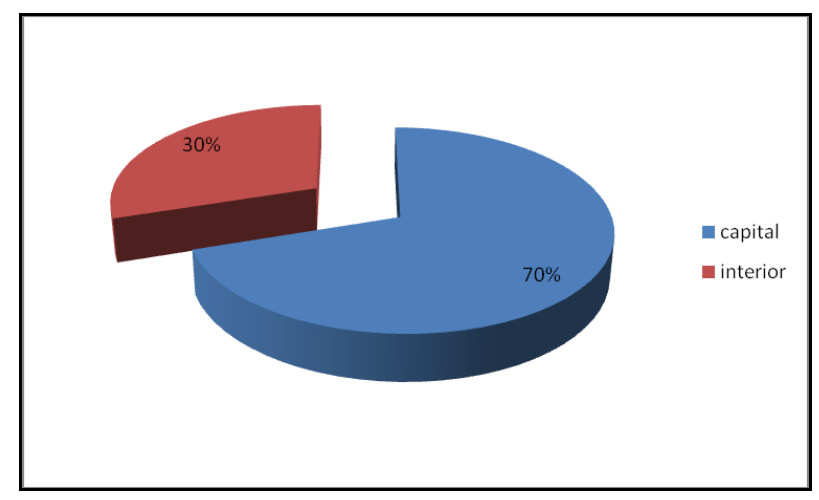


Figura 5 Proporção de participações do interior e da capital do estado de São Paulo (\%)

O processo de "leitura" dos comentários apresentados foi de fundamental importância para que uma eficiente interpretação para se extrair o mais próximo possível aquilo que o respondente da pesquisa quis expressar. A linguagem dos comentários é, em geral, coloquial e, em muitas situações, as frases não eram bem construídas, com linguagem pouco entendível. Se de um lado este fato pode dificultar o entendimento, por outro, a expressão do sentimento das pessoas era mais natural. O processo de leitura é subjetivo, evidentemente, onde se procura entender a forma de expressão do respondente sem fazer uma interpretação imprecisa. Nesta etapa, extraiu-se até 3 sugestões citadas como alternativas ao transporte individual como meio de locomoção.

A situação caótica do trânsito tende a piorar em São Paulo, principalmente por causa do aumento da frota paulistana de veículos de 2008 para 2009, que foi de 30\%, e no interior do estado foi ainda bem maior, 77\%, segundo a reportagem do jornalista no site de notícias UOL (Balza, 2009). O grande aumento da frota no interior do estado, ou seja, em cidades de médio e pequeno portes, mostra que os problemas de trânsito também acenam a possibilidade de agravamento, com resultados apontando para maiores índices de congestionamentos e de acidentalidade viária. Os tipos de manifestações mostram certa irritação das pessoas com a realidade dos fatos.

A participação masculina na pesquisa foi expressiva (77\% das respostas), quando comparada com a das mulheres (ver Figura 6), mas em menor nível que no trabalho de Raia Jr. et al. (2008), onde os comentários dos homens chegaram a 94\% do total, embora o alvo da pesquisa neste caso fosse a realidade da Região Metropolitana de São Paulo. 


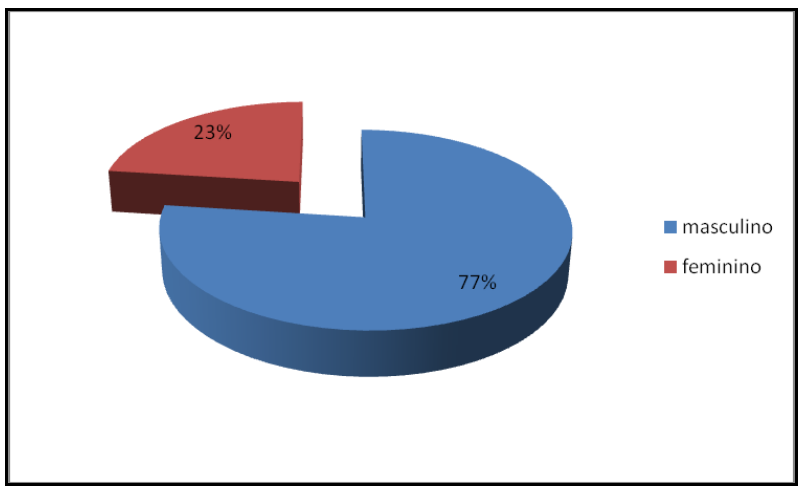

Figura 6 Proporção de respondentes, segundo o sexo (\%)

Com relação à principal questão colocada na pesquisa, ou seja, "você trocaria seu carro por um transporte público ou alternativo?", 30\% responderam que não utilizariam outro meio de transporte; $21 \%$ disseram que trocariam o transporte motorizado individual por transporte alternativo. Quase metade das respostas, no entanto, teceram seus comentários e críticas sem, no entanto, apresentar uma resposta objetiva (Figura 7).

Dentre os meios alternativos de transportes pelos quais os respondentes aceitariam passar a usar, o metrô foi apontado como a melhor alternativa ao transporte individual, por quase $17 \%$ dos participantes, em segundo, o ônibus, $12 \%$, em terceiro, o transporte coletivo em geral (sem explicitar qual), citado por quase 8\%. A bicicleta, como meio alternativo, foi citada em $6 \%$ das participações, demonstrando que ela também pode ser um meio alternativo de transporte atraente para viagens cotidianas. A Figura 8 mostra os modos alternativos citados e suas participações no total de respostas. 


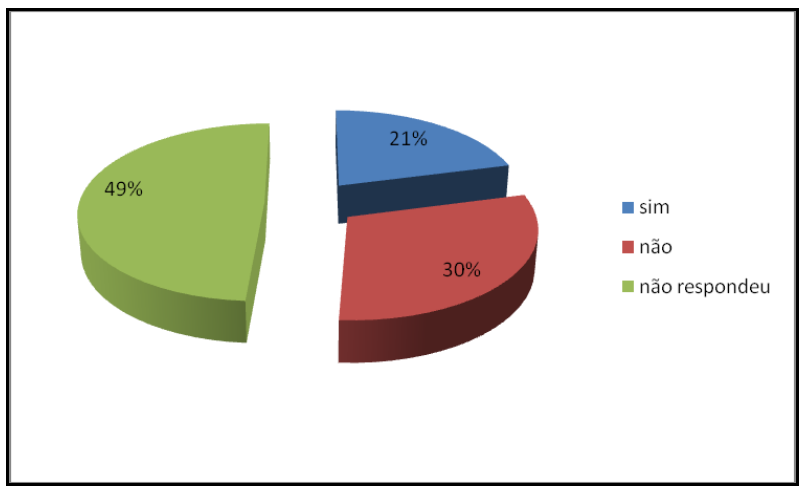

Figura 7 Respostas relacionadas à troca do modo individual para o alternativo (\%)

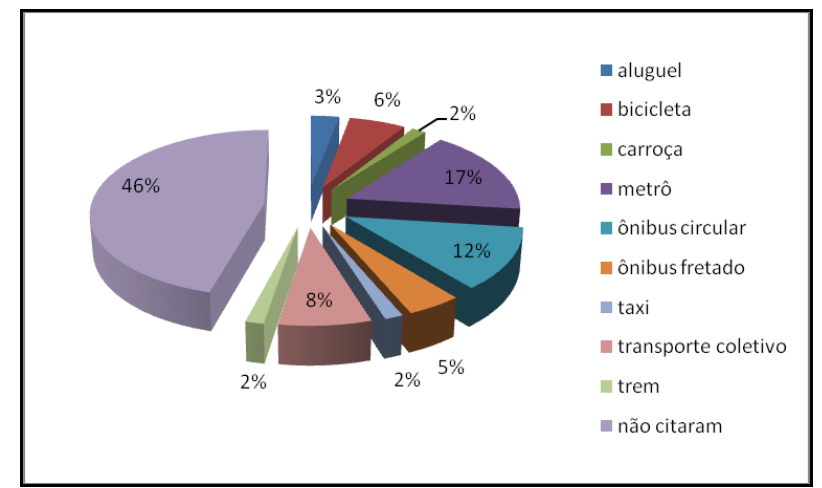

Figura 8 Modos de transporte alternativos citados pelos participantes (\%)

Também procurou-se conhecer os principais problemas encontrados no transporte coletivo, hoje disponível. 35\% das respostas apontaram que o transporte coletivo é de maneira geral ruim; $17 \%$, a lotação; $13 \%$ o atraso excessivo do sistema; $11 \%$, a falta de conforto; e $9 \%$ entendem que o trânsito contribui muito para que o transporte coletivo seja de qualidade baixa (Figura 9). 


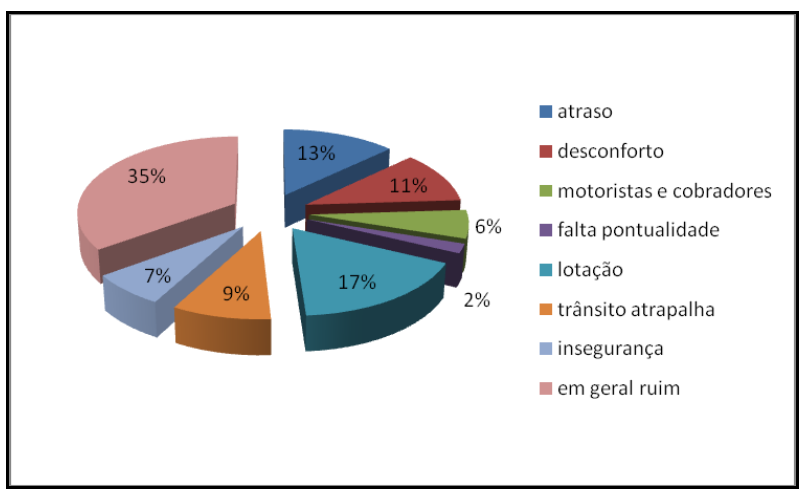

Figura 9 Motivos pelos quais não usaria o transporte coletivo (\%)

Um aspecto considerado significativo que pôde ser prospectado na análise das manifestações desse grupo de pessoas, foi aquele relacionado com as preocupações ambientais. Afinal, tem sido relativamente frequente a apresentação, na grande mídia, noticiários, comentários, reportagens, etc., enfocando os impactos ambientais produzidos pela ação do homem contemporâneo, particularmente no trânsito. Nas grandes cidades, segundo Raia Jr. et al. (2008), o trânsito chega a representar 50\% das emissões de poluentes no ar, com graves conseqüências ambientais, aumentando o efeito estufa.

Diferentemente do que se podia esperar deste grupo de pessoas, e que causou certa apreensão, foi que apenas $17 \%$ dos participantes denotaram algum tipo de preocupação relacionada com o meio ambiente e a sustentabilidade, associada com a operação do trânsito. Apesar da amostra de respondentes ser relativamente pequena, sem significação estatística, não deixa de ser preocupante certa alienação das pessoas em relação ao assunto, e a pequena associação dos problemas com o meio ambiente.

A expectativa prévia dos pesquisadores era que, hipoteticamente, por serem pessoas que convivem cotidianamente com os impactos da poluição do ar, do barulho, nas doenças respiratórias, pudessem ter presentes, além obviamente dos aspectos operacionais de seus deslocamentos, com as questões ambientais, o que não ocorreu. $\mathrm{O}$ índice de pessoas preocupadas com o meio ambiente e sustentabilidade desta pesquisa 
foi considerado baixo, porém, foi um pouco maior daquele registrado na pesquisa de Raia Jr. et al. (2008), onde apenas 10\% externaram sua preocupação com o tema. Há que se citar que o objeto daquela pesquisa era "como o paulistano compreende e se sensibiliza com os problemas do caótico trânsito de São Paulo".

O último aspecto observado nos comentários apresentados, foi se os respondentes entendiam haver alguma concorrência, direta ou indireta, por parte do estado, em qualquer dos três níveis, órgãos públicos ou privados, a sociedade, etc., para a situação crítica do trânsito e dos transportes, em geral. Esses resultados apontaram que $27 \%$ dos respondentes entendem que cabe culpa ao poder executivo e $25 \%$ ao poder legislativo. $O$ "poder econômico" foi citado em $6 \%$ das respostas como tendo culpa solidária na séria crise que as cidades brasileiras enfrentam nos setores de trânsito e transporte coletivo.

\section{CONCLUSÕES}

O objetivo deste trabalho foi apresentar os resultados de uma pesquisa explanatória realizada via site da UOL Notícias, onde foram analisados comentários relacionados com a questão apresentada "Você trocaria seu carro por um transporte público ou alternativo? Como as respostas eram do tipo abertas, espontâneas, cada um escreveu aquilo que bem entendia. Apesar grupo pesquisado não ter significação estatística, os resultados pareceram interessantes, mesmo se eles devem ficar restritos somente ao grupo participante, sem inferência alguma.

A maioria dos respondentes era composta por homens, na maioria da capital de São Paulo. Não chamou a atenção que, em geral, o gênero masculino é mais propenso a participar deste tipo de pesquisa, principalmente aquelas relacionadas com os setores de trânsito e transportes. Apesar de todos os problemas enfrentados na atualidade com os 
setores de trânsito e transportes, apenas $21 \%$ se mostraram dispostos a mudar para um modo alternativo de transportes, em relação ao transporte motorizado individual. Isto, na verdade, é muito preocupante, pois mesmo com a massificação de informações sobre as modificações no clima, o efeito estufa, etc., ela parece não têm sensibilizado a população de maneira significativa. As pessoas ainda têm um pensamento muito individualista, pensando muito mais nas suas necessidades individuais do que a problemática coletiva associada aos graves problemas proporcionados pelo grande crescimento das frotas de automóveis e motocicletas, nas principais cidades brasileiras.

De maneira geral, fica muito clara a visão negativa que as pessoas têm sobre a qualidade (ou falta dela) dos sistemas de transporte coletivo urbano, principalmente na cidade de São Paulo. Ao menos com relação ao grupo pesquisado. Apesar de todos os problemas com o trânsito, congestionamentos, poluição, etc., essas pessoas não pretendem modificar o seu comportamento na escolha modal.

Depreende-se dos resultados, que o processo de modificação na matriz de transportes nas cidades brasileiras, particularmente, na Região Metropolitana de São Paulo, deverá ocorrer de forma relativamente traumática, já que, com a rápida e crescente ampliação da frota de veículos individuais, os problemas também crescem e se consolidam de forma igualmente veloz. Modificações na matriz de transportes certamente deverão ser precedidas de mudanças radicais na qualidade dos sistemas de transporte público, associadas com medidas impositivas e coercitivas para seu uso. Isto, evidentemente, deverá contribui para a melhoria da qualidade de vida, do meio ambiente e para a sustentabilidade das cidades.

\section{REFERÊNCIAS}


BALZA, G. Estado de São Paulo ganha mais de 1,2 milhões de veículos em 1 ano. Disponível em: http://noticias.uol.com.br/especiais/transito/2009/09/22/ult5848u59.jhtm. Acesso em: 15 out. 2009.

JLAA. Avaliação comparativa das modalidades de transporte público urbano. NTU: Curitiba, 2009.

FREDERICO, C. S.; NETTO, C. J. e PEREIRA, L. S. Transporte metropolitano e seus usuários. Estudos Avançados, 11(27), 413-428, 1997.

HAGEN, J. Bus Rapid Transit-BRT: experiências internacionais, ITDP-Institute for Transportation \& Development Policy. Disponível em: http://www.ntu.org.br/novosite/ arquivos/Jonas_Hagen.pdf. Acesso em: 28 jul. 2010.

Raia Jr., A. A.; Jammal, M. F. e Corrêa, F. Como o Paulistano Compreende e se Sensibiliza com os Problemas do Caótico Trânsito de São Paulo. Anais 3 Congresso Luso Brasileiro para o Planejamento, Urbano, Regional, Integrado e Sustentável, UNESP/USP/Universidade do Minho/UFSCar, Santos, 01-03 Outubro 2008.

WBCSD/CEBDS. Mobilidade 2030: vencendo os desafios da mobilidade, World Business Council for Sustainable Development, Conselho Empresarial Brasileiro para o Desenvolvimento Sustentável, Rio de Janeiro, 2004.

WHO. The World Health Report/02: reducing risks, promoting healthy life. Geneva, 2002. 